\title{
Perspective
}

PERSPECTIVE Actualité en histoire de l'art

2| 2009

L'Espagne

\section{Cultures de la représentation dans l'Espagne de la Réforme catholique}

Cultures of Representation in Counter-Reformation Spain

Kulturen der Repräsentation im Spanien der katholischen Reform

Culture della rappresentazione nell'Spagnadella Riforma cattolica

Culturas de la representación en la España de la Reforma Católica

\section{Felipe Pereda}

\section{OpenEdition}

Journals

\section{Édition électronique}

URL : http://journals.openedition.org/perspective/1386

DOI : 10.4000/perspective.1386

ISSN : 2269-7721

\section{Éditeur}

Institut national d'histoire de l'art

\section{Édition imprimée}

Date de publication : 30 juin 2009

Pagination : 287-300

ISSN : 1777-7852

Référence électronique

Felipe Pereda, "Cultures de la représentation dans l'Espagne de la Réforme catholique ", Perspective [En ligne], 2 | 2009, mis en ligne le 22 juillet 2014, consulté le 21 décembre 2020. URL : http:// journals.openedition.org/perspective/1386 ; DOI : https://doi.org/10.4000/perspective.1386 


\title{
Cultures de la représentation dans l'Espagne de la Réforme catholique
}

\author{
Felipe Pereda
}

\begin{abstract}
"Grattons un peu, et nous ne tarderons pas à découvrir [...] l'Inquisition immanente et diffuse, revêtue d'un formalisme bien peu strict sur les formes, et de cette gravité si peu sérieuse qu'est la vieille morgue castillane " ${ }^{1}$.
\end{abstract}

Jusqu'à la fin du XVIII ${ }^{e}$ siècle, la peinture et la sculpture espagnoles furent au service direct ou indirect de l'Église. Fruit de son patronage, représentant son univers imaginaire ou ses valeurs intrinsèques, elles représentèrent une partie essentielle de l'économie spirituelle des institutions religieuses. Toutefois, l'importance de ce champ de production artistique hispanique est aujourd'hui confrontée à un étrange paradoxe. Au moment même où sont organisées d'importantes expositions internationales sur ce thème, témoignant de l'intérêt croissant que la peinture et la sculpture religieuses suscitent en dehors de nos frontières, les études sur l'image religieuse en Espagne restent rares. De plus, si l'historiographie reconnaît que l'analyse de la " culture de l'image » (SCHMITT, 2002), qui est née en Europe, requiert une approche pluri-disciplinaire, voire anthropologique, la méthodologie employée est le plus souvent inappropriée compte tenu de la nature hybride de leur objet d'analyse. Dans les pages qui suivent, nous visons à mettre en lumière certaines des clés qui nous semblent nécessaires pour aborder l'étude de l'image religieuse de la Contre-Réforme, et plus concrètement celle de la monarchie hispanique, tout en présentant un bilan historiographique, malheureusement bien faible, de ces études en Espagne.

\section{L'étrange cas d'Antonio de la Vila : le culte de l'image dans l'Espagne baroque}

Dans les rapports judiciaires de l'Inquisition sévillane, on trouve le cas extravagant d'un certain Antonio de la Vila, un imprudent habitant de San Juan del Puerto - un village aux environs de Huelva - qui fut accusé en 1635 par neuf témoins différents d'avoir eu des mots et un comportement révélant un manque d'orthodoxie. Le plus intéressant de l'histoire, et ce que les juges de la Sainte Inquisition étudièrent manifestement avec le plus d'attention, est une curieuse anecdote qui eut lieu alors que l'accusé était en train de bavarder dans la rue avec un groupe de gens lors d'une journée d'été. Don Antonio, « voyant que quelques-unes des personnes qui l'accompagnaient s'écartaient de l'ombre projetée par une croix sur le sol pour l'éviter, rit puis marcha sur cette ombre $»^{2}$.

Felipe Pereda est professeur d'histoire de l'art à I'Universidad Autónoma de Madrid. Il participe au projet de recherche collectif «En las fronteras de las imágenes» (2009-2011), voué à l'étude des sources et des bases doctrinales de l'art religieux à l'époque moderne. Dans Las imágenes de la discordia. Política y poética de la imagen sagrada en la España del 400 (Madrid, 2007), il aborde de manière interdisciplinaire l'impact du conflit interreligieux sur la culture visuelle du règne des Rois Catholiques. II entreprend actuellement des recherches consacrées à l'image comme témoignage dans l'Espagne baroque. 
L'incident provoqua une telle surprise qu'il déclencha une discussion entre eux : " ces personnes ayant dit qu'elles s'écartaient afin de ne pas marcher sur l'ombre de la croix, l'accusé entra dans cette même ombre et déclara que laisser cette ombre couvrir sa tête et tout son corps c'était la révérer et l'estimer " ${ }^{3}$. Le ton ironique de cette remarque fait peu de doute, et quand Antonio parlait de la révérer, il faisait certainement allusion au soin qu'il mettait à protéger sa tête des rayons du soleil et non à l'attitude de dévotion que manifestaient ses voisins envers la forme de croix dessinée au sol.

On aurait pu espérer que l'histoire s'en fût tenue là, mais les inquisiteurs prirent l'affaire au sérieux et se virent forcés de trancher cette étrange polémique casuistique. En découla une petite digression sur la sémiotique de l'image : " ... et concernant la seconde proposition, que marcher à plusieurs reprises sur l'ombre de la croix que d'autres vénéraient comme une véritable croix relevait sans nul doute de l'hérésie. Mais qu'il ressortait de ses paroles, comme le confirmaient celles d'autres témoins, que son intention n'était pas de faire offense à la croix, que peut-être pour lui l'ombre de la croix n'était pas une croix, de même que l'ombre d'un homme n'est pas l'homme, et que pour cette raison marcher dessus n'avait aucune signification contrairement à un tel acte de la part d'une personne malintentionnée sur les questions de la foi et qui en serait devenue suspecte " ${ }^{4}$.

"Que peut-être pour lui l'ombre de la croix [n'est] pas une croix, de même que l'ombre de l'homme n'est pas l'homme... " : les inquisiteurs reconnaissaient à la fois l'innocence de l'accusé et l'éventualité que même une ombre puisse avoir une fonction de " signe " dans lequel s'identifieraient étroitement l'image, son empreinte matérielle et son référent.

Dans une récente publication, Hans Belting a établi les grandes lignes de ce qui est pour lui une lutte continue entre le signe et l'image tout au long du Moyen Âge et jusqu'au début des Temps modernes (Belting, 2005). Non seulement Belting refuse catégoriquement l'idée que les images soient des signes - indépendamment du fait qu'elles puissent fonctionner comme tels -, mais il soutient que les signes et les images se sont toujours opposés comme des alternatives adverses, à tel point que la " sémiotisation " des images se présente comme un effort historique des théologiens pour établir des frontières et exercer un contrôle sur le pouvoir autonome des images. Le débat entre iconodules et iconoclastes à Byzance jusqu'au concile de Nicée peut ainsi se comprendre comme l'affrontement entre les défenseurs et les partisans de l'utilisation de signes. Et de la crise iconoclaste à la naissance d'une "théorie du signe " dans l'Europe du haut Moyen Âge - ce que Belting situe entre le concile de Francfort et la rédaction des Libri Carolini (794-824) les " ennemis des images " trouvèrent dans leur réduction à des signes une stratégie pour les soumettre à leur contrôle (BELTING, 2005, p. 133-151).

L'histoire des images sous la monarchie catholique montre, comme l'illustre l'anecdote rapportée en introduction, une histoire difficile à inscrire dans ce schéma, ou tout du moins ce que l'on pourrait voir comme une progressive émancipation de l'image au cours des Temps modernes, conséquence qui semble implicite dans le raisonnement exposé. Ce n'est pas un cas isolé. Dans certaines des principales études sur la théorie de l'image ces dernières années se dessine un itinéraire où l'auto-référentialité du discours pictural (STOICHITA, 1993), son "immanence " (KRÜGER, 2001) et en définitif la construction d'un discours sur l'art autonome dans le passage de l'ère de l'image à l'ère de l' " art " (BELTING, 1990), font partie d'un processus de sécularisation de l'image qui semble toujours marqué par une certaine tendance (peut-être inévitable) à la téléologie. 
La culture figurative espagnole et ibéro-américaine est malheureusement restée extérieure à un débat dont l'axe géographique est toujours situé entre l'Italie et les Pays-Bas, absence particulièrement surprenante étant donné la récente prolifération de travaux sur l'image religieuse dans l'Europe moderne (citons, parmi les plus représentatifs, STOICHITA, 1996 ; BACCI, 1998 ; El divino pintor..., 2001 ; WOLF, 2002). Plutôt que de chercher à situer la culture espagnole par rapport à un modèle ou à un autre, notre intention est de montrer dans les pages qui suivent que certains des traits les plus spécifiques de la tradition artistique hispanique des Temps modernes apparaissent d'autant plus clairement que l'on aborde ces images non seulement à partir de l'émergence d'un discours esthétique autonome, mais aussi dans l'appréhension de deux domaines (artistique et religieux) distincts. En outre - et ce sera notre second fil conducteur - nous verrons que, en prenant en compte cette situation particulière, on abandonne un modèle d'évolution unique qui privilégie l'homogénéité, met l'accent sur la valeur du normatif et laisse de côté la particularité locale en faveur d'un autre modèle, plus sensible à l'hétérogénéité profonde - au sens large - de l'image religieuse dans l'Europe moderne.

Mais revenons à notre récit. Le verdict des inquisiteurs sévillans que dut affronter Antonio de la Vila en 1635 n'était pas uniquement le fruit de leur bon sens; il était aussi le résultat d'une discussion qui avait été soumise aux inquisiteurs à de nombreuses reprises et dont la casuistique avait été " résolue " au moins quatre-vingts ans plus tôt. En fait, on peut en retrouver les lointaines origines en remontant aux premières années de fonctionnement du Saint-Office, quand, justement avec la contestation des conversos (juifs convertis au catholicisme) et des morisques, les images commencèrent à être reconnues comme les signes extérieurs d'une pratique religieuse normalisée (PEREDA, 2007).

Il faut considérer cette situation dans le contexte d'une Église qui, contrairement à l'Église orientale, n'avait pas développé une théorie - et encore moins une théologie de l'image, ce qui, de par la multiplication de la production figurative ou artistique dans presque toute l'Europe à cette époque, avait laissé le champ libre à l'apparition d'interprétations très diverses concernant le statut des représentations visuelles et leur rôle dans la pratique religieuse. Les différences sont particulièrement conséquentes quand on prend en considération les opinions que des théologiens de différentes obédiences défendaient au sujet du culte qui devait leur être rendu. Outre les mouvements spirituels qui avaient rejeté toute forme de culte (comme par exemple les Hussites ou les Lollards), on distinguait clairement, à la fin du Moyen Âge, les opinions de ceux qui, sur la voie ouverte par Thomas d'Aquin, revendiquaient pour les images le même type ou degré de culte que celui qui devait être rendu à ceux qu'elles représentaient. Face à ces derniers, se faisaient entendre d'autres théologiens comme Durand de Saint-Pourçain, Robert Holkot ou Pico della Mirandola qui, indépendamment de la position de saint Thomas, qui refusait le fait que les images puissent abriter quelque forme de vertu particulière et affirmait qu'elles n'étaient que de simples intermédiaires à travers lesquels atteindre leurs référents, observaient dans ce point de vue, même avec ces précautions, un risque pour le moins évident d'idolâtrie : selon ces auteurs, la position de saint Thomas, même si elle pouvait sembler irréfutable du point de vue de la logique, favorisait des comportements clairement hétérodoxes.

À la moitié du XVI ${ }^{e}$ siècle, à l'aube du concile de Trente, cet épineux problème n'était pas résolu, et il ne le serait d'ailleurs jamais. C'est précisément l'attitude ambiguë adoptée par les Pères du concile qui permit un foisonnement de positions hétérogènes au sein de l'Église catholique. Nous verrons plus loin dans quelle mesure on peut les relier à 
différentes traditions figuratives. Pour le moment, il est important de souligner qu'en Espagne, en tout cas du point de vue de l'organisme chargé de surveiller l'orthodoxie des sujets de la Monarchie catholique, on avait penché très tôt pour la position " thomiste ", selon laquelle les images devraient être l'objet du plus haut degré de reconnaissance cultuelle.

Presque un siècle avant l'incident de l'ombre, le 22 décembre 1560, deux célèbres "hérétiques ", Costantino Ponce de la Fuente - l'un des prédicateurs les plus célèbres de son siècle - et le chanoine Juan Gil, un membre du chapitre ecclésiastique sévillan, plus connu sous le nom de docteur Egidio, furent persécutés, jugés et condamnés par l'Inquisition. Tous deux étaient accusés d'être luthériens. On a conservé du second son acte d'abjuration : dix points dans lesquels le docteur Egidio se rétractait de toutes les affirmations que le Saint Tribunal avait condamnées comme étant hérétiques. Le document contient donc aussi bien l'énonciation erronée que celle que le Saint-Office considérait orthodoxe. Deux des dix points en question concernent les images et font référence à la même erreur selon deux positions ou perspectives différentes ${ }^{5}$. L'insistance est la preuve, s'il en est, de l'importance de ce sujet pour les inquisiteurs. Pourtant, les chercheurs et les historiens de l'art semblent n'y avoir jamais prêté attention : bien au contraire, la recherche des dernières années s'est principalement concentrée sur des cas de censure et sur le mécénat (voir notamment PINTO, 1978, SCHOLZ-HÄNSEL, 1994, CORDERO DE CIRIA, 1997).

Au point numéro huit, Egidio abjura la phrase selon laquelle « il ne faut adorer que Dieu » et son affirmation que les Sévillans commettaient l'idolâtrie avec les images de la Vierge quand ils la sortaient en procession, ce qui supposait une grande offense envers Dieu. Il invoquait deux raisons pour ces dires : d'une part les interdits vétérotestamentaires, et $d^{\prime}$ autre part les " conciles" (allusion probable au concile d'Elvire) ${ }^{6}$. La formulation orthodoxe qu'il se vit contraint de faire sienne affirmait deux choses : que la croix doit recevoir la même forme de culte que son référent, le Christ. La seconde, glissée subtilement dans le texte, étendait cette même forme d'adoration - la latrie - du "signe " de la croix aux images.

Au point suivant de son abjuration, le Saint Tribunal entrait dans des subtilités en se concentrant sur la qualité et le niveau de culte à rendre aux signes chrétiens et aux images en tant que tels : "De même, j'ai dit que la croix ne devait pas être adorée en sa qualité de croix, que seul Dieu devait être adoré et rien d'autre " ${ }^{7}$. L'affirmation du Docteur Gil aurait semblé parfaitement adéquate aux oreilles de bien des théologiens et même, osons le dire, tout à fait orthodoxe pour la majorité d'entre eux : Egidio ne refusait pas le culte des images, mais plutôt l'idée qu'elles puissent être l'objet du même type de dévotion que leurs référents. Autrement dit, il établissait une gradation entre le culte rendu aux représentations et celui de ceux qu'elles représentaient. Comme on le voit, la question discutée était d'ordre sémiotique : il s'agissait de savoir dans quelle mesure les images représentent les réalités absentes dont elles occupent la place. La formule sous laquelle abjura le docteur Egidio est sans équivoque : " ... la croix doit être adorée de la même adoration de latrie qu'on adore Jésus parce qu'on l'adore en tant qu'objet où figure le représenté et ainsi je dis que la croix et les images ne servent pas seulement à nous souvenir comme l'écriture de Dieu et des saints que nous devons adorer mais en tant que signes où sont représentés Dieu et les saints elles doivent être adorées elles-mêmes " ${ }^{8}$.

Ainsi, c'est précisément en leur qualité de signes que les images méritent un plus grand respect. Au-delà de la fonction traditionnelle de l'image comme mémoire des saints, stimulant pour la dévotion ou instrument éducatif - rôle qui allait justement être mis en avant dans le célèbre décret sur les images du concile alors en cours -, les images sont 
des représentations de Dieu, de la Vierge ou des saints. Elles sont identifiées à eux et par conséquent requièrent du fidèle la même révérence qui leur est due. Aux yeux du chrétien, alors, l'image du Christ est présentée comme s'il s'agissait du Christ lui-même.

À la lumière d'une telle théorie de l'image, il devient plus compréhensible, ce qui ne veut pas dire raisonnable, que le Saint-Office ait pu prendre en considération les accusations qu'un groupe d'habitants de San Juan del Puerto proférèrent à l'encontre d'un voisin qui avait refusé de renoncer au généreux abri que lui offrait l'ombre d'une croix en une chaude journée d'été.

Ceci dit, en quoi cette position est-elle particulière ? Dans quelle mesure et pour qui aurait-elle été exceptionnelle ? Dans un célèbre article consacré à l'élaboration du décret sur les images du concile de Trente, Hubert Jedin a montré la tâche difficile à laquelle s'étaient confrontés les Pères conciliaires pour résoudre une affaire sur laquelle il existait un désaccord notable (JEDIN, 1966). Dans les années immédiatement antérieures à la rédaction du décret, les conflits religieux, les critiques sur la prolifération des images saintes dans le monde catholique, ainsi que l'irruption de groupes iconoclastes, avaient hâté la réflexion de l'Église de Rome (WIRTH, 2000). Tandis que certains auteurs, en particulier au sein de l'ordre des dominicains, serrèrent les rangs autour de la logique fermée proposée par le système thomiste - ce qui est le cas, par exemple, d'ORY, 1552) -, nombreuses furent les voix qui s'opposèrent explicitement à la reconnaissance pour les images d'une forme de représentation leur assurant le même type de culte qu'à leurs référents. L'évêque de Guadix, Martín Pérez de Ayala, par exemple, dans son analyse détaillée de la question en 1548 (PÉREZ DE AYALA, 1548), s'appuyant sur la tradition historique de l'Église - ce qui incluait la reconnaissance de quelques-unes des images saintes occidentales les plus connues et de leurs légendes (du Mandylion aux images attribuées à saint Luc) - et après avoir reconnu et accepté qu'on devait leur rendre un culte, rejetait cependant la proposition de l'Aquinate, démontant la subtilité scolastique avec la logique du bon sens : il était impossible de demander au peuple d'adorer les images de la même façon que les saints qu'elles représentaient tout en faisant la distinction entre les deux réalités, c'est-à-dire sans tomber dans le péché d'idolâtrie. Mais l'évêque de Guadix n'était pas un cas isolé. Le juriste Konrad Braun (BRAUN, 1547) avait également rejeté la latrie pour les crucifix, tandis que, pour Ambrosius Catharinus (CATHARINUS, 1552), les images devaient bien sûr être vénérées mais toujours aliquo modo adorandae, non quidem latria... [dans une autre forme, pas celle de la latrie] (JEDIN, 1966, p. 469). À peine dix ans plus tard, le docteur Egidio mordit la poussière de l'estrade du Saint Tribunal pour avoir dit exactement la même chose.

La position adoptée par le concile de Trente fut particulièrement ambiguë sur ce point. Tandis que le décret se réfugiait derrière l'autorité de Nicée (787), alléguant que le culte concernait le représenté et non l'image elle-même, affirmation qui prenait un sens clairement apologétique face aux accusations de la Réforme -, son argumentation avait un poids fondamentalement ecclésiologique : il s'agissait de demander aux évêques de soumettre les peintres à un plus grand contrôle des images qu'ils produisaient et de les utiliser pour éduquer convenablement leurs ouailles. Cela étant, le concile ne résolvait pas le problème du type de culte qui devait être rendu aux images, justement la question qui avait engendré le plus de débats dans les années antérieures. Dans une ambiguïté calculée, le décret en permettait le culte, contournant l'épineux sujet qui avait divisé les théologiens du catholicisme : la pertinence du culte de latrie pour le crucifix et par extension la nature des images en tant que représentation de réalités spirituelles absentes. 
Le résultat immédiat en fut un flagrant manque d’homogénéité dans la position de l’Église de la Contre-Réforme, diversité qui se déclinait différemment selon la tradition intellectuelle du théologien qui se prononçait, mais aussi selon son origine géographique (BOESPFLUG, CHRISTIN, 2007). L'abjuration du docteur Egidio y occupe une place exceptionnelle : d'abord, le point de vue que le Saint-Office jugea hérétique avait été soutenu par bien d'autres théologiens, dans la péninsule ibérique ou ailleurs, sans susciter aucune suspicion ; quant à la formulation, considérée exempte d'erreur, elle se situait en un point qui avait été critiqué dans les rangs de l'Église au motif qu'elle entraînait un risque accru d'hérésie. Pour conclure et d'après les juges du Saint-Office, les images doivent alors recevoir exactement le même culte que leurs référents : la plus grande forme d'adoration, la latrie, dans le cas des représentations du Christ, l'hyperdulie pour la Vierge, et la dulie pour les saints. Du point de vue du culte, les images sont comme ces réalités qu'elles remplacent.

Alors que l'historiographie a été très sensible à l'importance du décret sur les images du concile de Trente pour l'analyse de la production figurative, la question du culte des images (comme celui de ces images au culte spécifique, dites "sacrées ") n'a reçu qu'une attention marginale. Par conséquent, le caractère homogène des fondements de la culture visuelle a été souligné (par exemple pour le caractère d'exemplarité de l'imagerie que défendait le concile), et les divergences (précisément là où l'ambiguïté des Pères de Trente permettait, si elle ne les encourageait pas, une plus grande diversité d'opinions) en ont

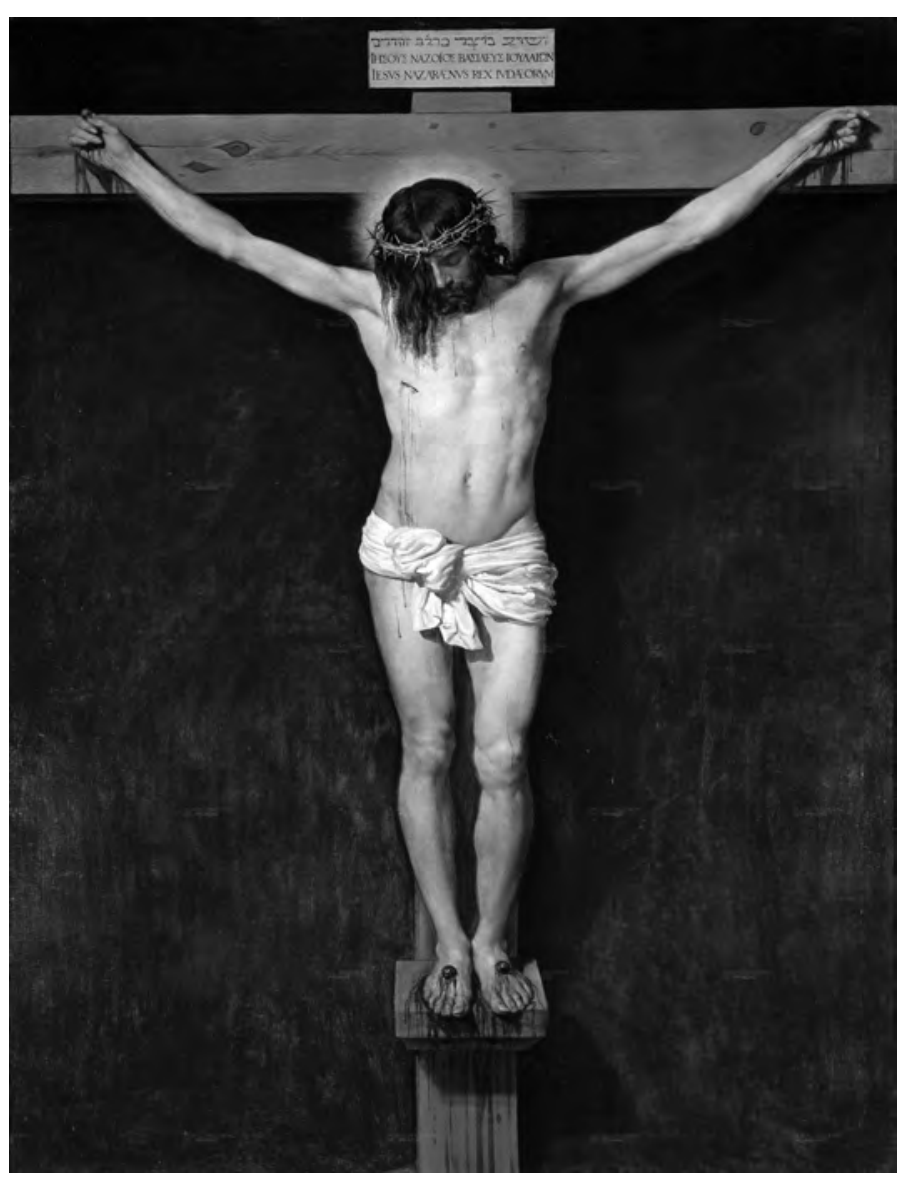
été sous-estimées. Comme nous le verrons par la suite, les recommandations du concile sur la valeur des images dans la tradition chrétienne furent considérées et menées de façon très diverse (avec des différences qu'il conviendrait d'explorer, non seulement en fonction de la géographie, mais aussi des doctrines propres aux différents ordres religieux), ce qui conditionna, à l'évidence, la culture visuelle qui en découla.

Dernièrement, le problème de l'importance du discours des théologiens sur les images et la production artistique a éveillé des opinions contrastées : tandis que certains auteurs maintiennent leur relative indépendance (BELTING, 1994), d'autres ont souligné le caractère paradigmatique de la 
théologie sur n'importe quelle autre théorie de l'image (FREEDBERG, 1992). Pourtant, l'incorporation de cette problématique dans l'analyse de l'image religieuse pourrait non seulement offrir une perspective différente pour son interprétation, mais aussi - ce qui actuellement nous semble le plus important - pour repenser la " géographie " de l'imagerie du monde catholique afin de mieux mettre en valeur les différentes façons dont l'esprit de la Réforme catholique fut décliné dans des contextes aussi divers que ceux de l'Italie, l'Espagne ou les colonies du Nouveau Monde (KAUfMANN, 2004).

\section{Le Christ de Velázquez comme image sainte : théorie du culte et discours de la représentation}

Une image aussi célèbre et, malgré sa simplicité, aussi élusive que la Crucifixion de Velázquez (Madrid, Museo del Prado ; fig. 1) peut nous servir de motif pour développer cette idée. Réalisé par le Sévillan au début des années 1630, probablement au retour de son premier voyage en Italie, le tableau présente le Christ sur la croix de façon absolument inédite, emblématique de l'art du maître et de l'école espagnole dans son ensemble. Son histoire n'est pas moins caractéristique. Tandis que certains pensent que l'œuvre fut commandée par Jerónimo de Villanueva en réparation du scandaleux procès inquisitorial au cours duquel les sœurs bénédictines de Saint-Placide (et lui-même en tant que bienfaiteur) furent accusées d'alumbradismo, un courant d'illuminisme chrétien en Espagne (BROWN, 1986), d'autres y voient une sorte d'ex-voto expiatoire d'un des cas de profanation rituelle qui eut le plus de répercussion durant ce siècle : en 1630, quatre conversos portugais (deux couples) furent arrêtés et accusés d'avoir fouetté à plusieurs reprises un crucifix à leur domicile madrilène de la rue Infantas, répétant ainsi sur la sculpture les tourments de la Passion du $\mathrm{Christ}^{9}$ (fig. 2). Le procès aboutit à un autodafé où les quatre accusés furent publiquement " relaxés " (exécutés) en présence du roi et de la reine (CEBALLos, 2004). Cette anecdote entraîna un véritable déchaînement du culte du crucifix, avec des cérémonies expiatoires et même des joutes poétiques, où les images jouèrent un rôle fondamental. Il ne serait donc pas étonnant que Velázquez se soit vu directement ou indirectement affecté par ces événements.

Peu d'images de ce siècle atteignent un degré de solennité comparable à celui du Christ de Saint-Placide. Pour cela, Velázquez a employé une stratégie qu'on qualifierait aujourd'hui d'hyperréaliste, qui détache le corps du Christ de la toile comme s'il en surgissait, indépendant du support matériel sur lequel il apparaît. Il n'est donc pas étonnant que le Christ de Velázquez ait été étudié en tant que représen-

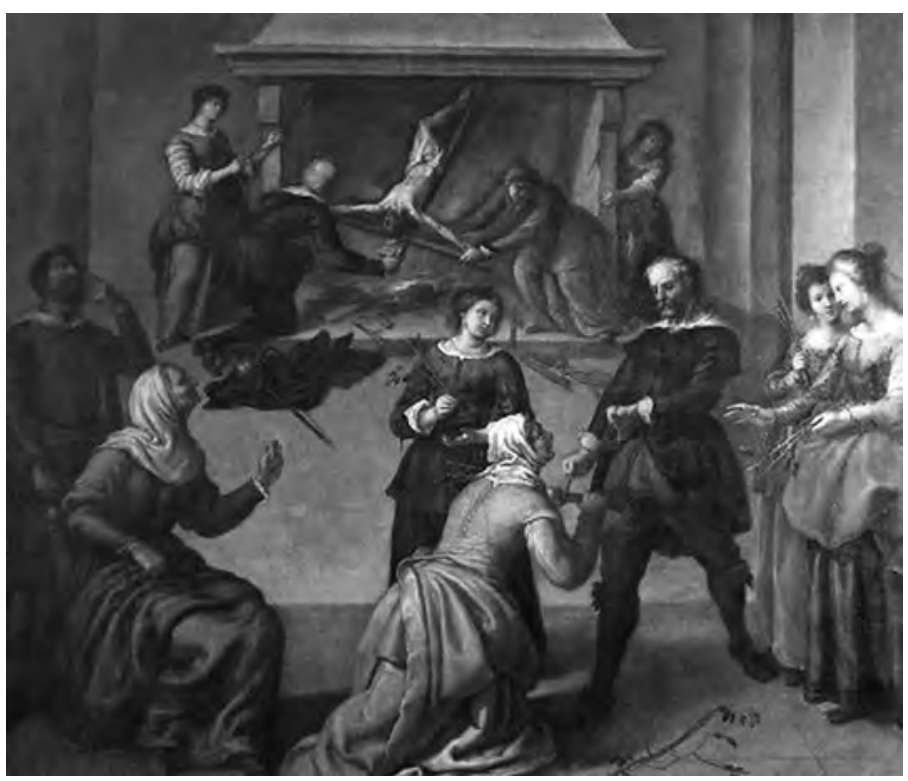

2. Francisco Camilo, Outrages à un crucifix, dit Cristo de la Paciencia, 1651, Madrid, Museo Nacional del Prado. 
3. Gregorio

Fernández, le Christ mort, 1605, Madrid, Convento de San Plácido.

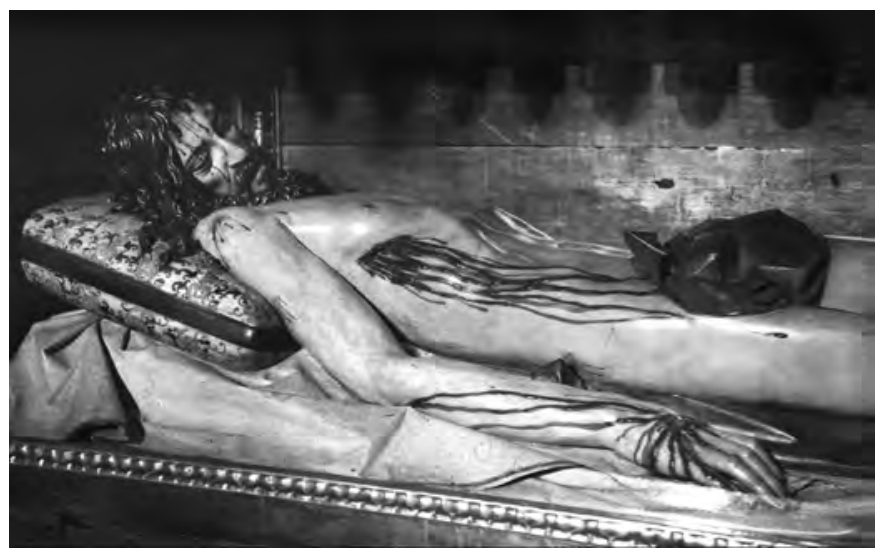

tation relevant de la sculpture (Ceballos, 2004 ; fig. 3), ou que l'historien Julián Gállego ait utilisé le terme de "santos estatua " pour faire référence aux représentations espagnoles $\mathrm{du}$ baroque qui cherchaient ainsi à isoler l'image de son support (GÁLLEGO, 1991).

L'illusionnisme auquel est parvenu Velázquez a peu de rapports avec une simple représentation " réaliste " et relève d'une habile manipulation des lois de la représentation picturale. La toile présente en dimensions réelles le corps sans vie du Christ qui se détache sur un fond neutre dont il est impossible de déterminer la nature. Une douce lumière éclaire le corps par la gauche, projetant de légères ombres sur son support : contours des bras et des mains, intérieur des jambes, dessous des pieds transpercés. La partie correspondant à l'arrière de la croix est sensiblement plus sombre, mais cette ombre ne permet pas pour autant de situer l'instrument du martyre dans un espace construit. La présence des ombres, si elle met en valeur le volume du corps, ne l'assoit nullement dans l'espace et vient souligner au contraire le manque total d'épaisseur du support (GROOTENBoer, 2005, p. 21-59).

L'agencement de la croix sur la toile accentue ce paradoxe. D'une part, le madrier, parfaitement droit, est placé de façon orthogonale et coïncide avec les bords de la toile de sorte que l'on pourrait le confondre avec les montants du châssis. Bien que complètement orthogonal, on distingue l'extrémité inférieure de la croix et sa base, légèrement fuyante, comme si le spectateur la voyait depuis une position en contrebas, comme prosterné, sans que cela affecte la projection spatiale de l'image. À cela s'ajoute un effet de proximité du corps du Christ produit par le dessin à quelques centimètres du bord inférieur de la toile, ses pieds se trouvant en dessous de l'horizon visuel du spectateur ${ }^{10}$, et non décentré vers la zone supérieure, comme c'est le plus fréquent et semble l'exiger la logique historique de l'épisode représenté.

Le Christ, vu de bas en haut et dans un espace dépourvu de profondeur, joue ainsi un impossible équilibre entre la distance qu'exigerait sa projection orthogonale et la proximité du spectateur. Il semble en effet que Velázquez se soit employé à construire une image qui place le spectateur en présence du crucifié. Les lois de la mimésis ne suffisent pas à expliquer la particularité d'un tableau qui porte les conditions de la représentation à une extrémité où l'image ne semble pas être la reproduction d'une réalité absente mais la manifestation d'une présence sacrée. Autrement dit, l'image n'est plus l'imitation d'un fragment de la réalité mais est présentée comme la véritable incarnation de son modèle. Pour reprendre les mots de Louis Marin à propos de l'Ex-voto de Philippe de Champaigne (1662, Paris, Musée du Louvre ; fig. 4) montrant un effet similaire : «elle pousserait si loin son intention mimétique [...] que sa dimension réflexive serait en quelque sorte effacée..." (MARIN, 1985, p. 190, 1994) ${ }^{11}$.

La convergence d'un modèle de représentation comme celui que nous venons de décrire et la " théorie de la représentation » de l'image sainte que le Saint-Office avait défendue de façon systématique semble évidente. Il serait simpliste, voire naïf, de prétendre que la seconde contient la clé pour comprendre la première, mais cette coïncidence - et 
c'est en tout cas la thèse de cet article - offre une perspective qui peut faire avancer la réflexion sur ce qui unit et ce qui sépare la culture artistique des territoires de la monarchie catholique, ou plus exactement son "imagerie ", du contexte général européen.

Le passage d'un modèle de représentation figuratif à un modèle cultuel est-il possible? Ou s'agit-il de deux discours complètement indépendants ? Une réponse possible serait d'étudier le contexte social de l'image, sa fonction (CIVIL et al., 2008). Malheureusement, comme nous venons de le voir, ce point n'a pas pu être éclairci. L'alternative que nous suivrons maintenant passe par un exercice de lecture intertextuelle - au sens propre - des deux aspects, religieux et artistique, de la représentation.

L'absence de définition du concile de Trente concernant le culte à rendre aux images, ainsi que l'insistance apologétique sur le fait qu'elles ne possèdent aucune virtus intrinsèque, ne fut pas un obstacle à la multiplication des " images saintes " durant les Temps modernes ; au contraire, le Baroque est par excellence la période de prolifération de sanctuaires dédiés aux images miraculeuses, et sa rhétorique visuelle fut un instrument d'une incontestable valeur dans leur construction auratique. Les publications sur ce phénomène se sont multipliées ces dernières années (WOLF, 1990 ; GANZ, HENKEL, 2004, 2007 ; THUNØ, 2004 ; pour l'Espagne, SCHRAEDER, 2008). En même temps, les traités De imaginibus - de Carlo à Federico Borromeo -, publiés sous l'égide du concile interprétèrent le décret dans le même esprit de prudence, en maintenant la même distance inévitable entre les images et les réalités spirituelles qu'elles substituaient, et en rejetant les théories thomistes de la représentation qui avaient circulé dans les années antérieures.

Le meilleur exemple en est sûrement Gabriele Paleotti (1522-1597) qui, comme l'a mentionné Pamela Jones, a écrit un traité sous le signe de l'universalité dans la définition du pouvoir des images et dans le service qu'elles pouvaient offrir à une Église dont les frontières géographiques s'étaient vertigineusement étendues (JONES, 1995). Dans son Discorso intorno alle immagini sacre e profane (Bologne, 1582), traité qui à fait l'objet dernièrement d'une attention croissante (PRODI, 1965 ; HeCHT, 1997 ; STEINEMANN, 2006), l'évêque de Bologne introduit son explication du « Vero modo di venerare le immagine sacre secondo principi cristiani ed il culto ad esse dovuto ", [véritable manière de vénérer les images sacrées selon les principes chrétiens et le culte qui leur est dû] taxant par deux fois de pazzia (folie) l'idée que la matière sensible puisse renfermer un contenu spirituel (PALEOTTI, [1582] 2002, p. 90-93). Les images sont objet de "vénération " ou " révérence ", mais seulement en raison du devoir qui est celui du fidèle d'honorer leur mémoire. En réservant le culte de latrie à la seule Eucharistie, on maintient les images loin de toute forme de sacramentalisation et leur culte dans une subordination incontournable.

Mais ce qui reflète le mieux la subtilité avec laquelle Paleotti a abordé la question du culte, c'est de le lire à travers le regard de son imitateur attentif et intéressé, le bien moins subtil Francisco Pacheco. Son Arte de la Pintura (Séville, 1649 ; fig. 5) n'est pas un traité d'images mais de peinture, donc un genre totalement différent. Or, le beau-père de Diego Velázquez intégra non seulement un appendice sur la représentation correcte des images dans son

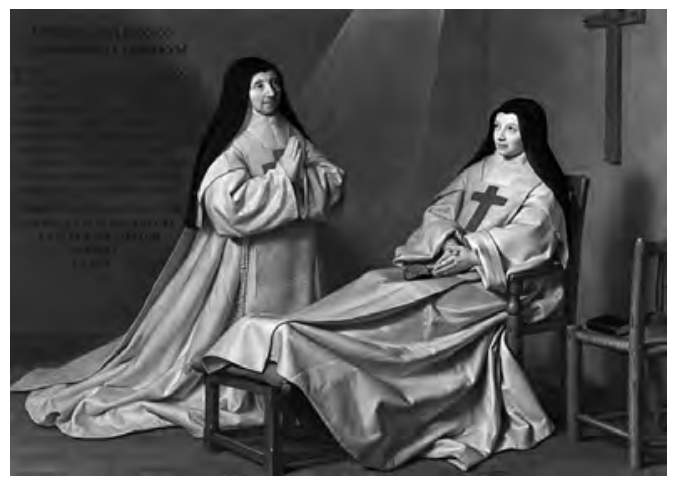

4. Philippe de Champaigne, Ex-voto, 1662, Paris, Musée du Louvre. 
livre premier "Antigüedad y grandezas de la pintura " mais aussi un long chapitre intitulé " fin y fruto ", qui n'est autre que la traduction quasi littérale du chapitre antérieurement cité du livre de Paleotti. Quasi littérale, car Pacheco, bien qu'il affirme se limiter à retranscrire les mots de l'évêque de Bologne, qu'il cite comme indiscutable source d'autorité en la matière, en réalité réécrit et complète Paleotti là où celui-ci minimise le culte des images saintes. Un seul exemple suffira à illustrer cet aspect de l'Arte de la Pintura jusqu'ici passé inaperçu ${ }^{12}$. Comme nous l'avons dit plus haut, Paleotti analysait le culte en marge des représentations religieuses, comme quelque chose concernant les images spirituelles et applicable aux signes visuels seulement de façon subsidiaire. C'est ce que rapporte aussi Pacheco dans sa traduction, mais avec le développement suivant, signalé ici en caractères italiques : "Et enfin voici, nécessaire à ce discours (qui, bien que bref, n'en est pas moins important) les trois formes d'adoration qui existent pour les images saintes. La première, nommée Latrie, est réservée à Dieu le Père, son fils et l’Esprit saint, à leurs divines images et au Très Saint Sacrement de l'autel [...] ; l'homme doit témoigner le culte de Latrie à l'excellence à la perfection absolue, laquelle ne se trouve que dans le premier principe de toutes les créatures, Dieu, auteur et créateur et gouverneur de l'univers ${ }^{13}$.

Ensuite, Pacheco - sans en avertir en rien le lecteur - introduit un nouveau paragraphe de son cru (toujours en italiques) : "Cette même adoration doit être rendue aussi à la plus petite partie du bois de la Très Sainte Croix sur laquelle est mort notre Seigneur, même si elle n'en a pas la forme, pour tout ce qui participe en lui à l'auvre de notre rédemption, et pour le contact de son très saint corps et de son sang divin, et si elle a une forme de croix, parce qu'elle représente le Seigneur lui-même cloué dessus. Et de la même façon, pour cette troisième raison, on doit révérer et adorer de latrie toutes les autres croix, de quelque matériau qu'elles soient, parce qu'elles figurent non seulement celle sur laquelle fut mis le Seigneur, mais sa personne divine même. La troisième manière, appelée Dulie, est une vénération et un signe de révérence anticipé, quand le Souverain Bien lui a prodigué les bienfaits de sa grandeur ${ }^{14}$.

Pacheco renchérit là où Paleotti séparait le culte de l'objet de celui de ses représentations : ainsi dans la révérence (hyperdulie) qu'il réclamait pour la Vierge, Pacheco ajoute " et à son image " (PACHECO, [1649] 1990, p. 264). En conséquence, l'édition espagnole

5. Frontispice de Francisco Pacheco, Arte de la Pintura, Séville, 1649 de Paleotti défigure complètement ses propos ; Pacheco

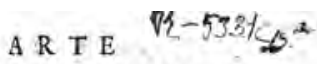

DE LA PINTVRA. SV ANTIGVEDAD. Y GRANDEZAS.

DESCRIVENSE CO5 HOMRAES EMTNENTES oue hasunto on ella, afia antiguas como inoderios, del dibu-

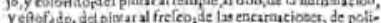

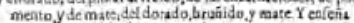
el modo de pintartiodaslaspinturas
fogratas.

PORERANCISCO PACBECO

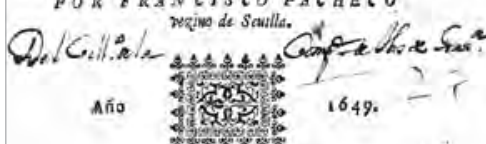

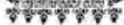

CON PRIVILEGIO.

En Soilld por Simen Favgrds inspreliar Le hir als Corrajeria.
- qui s'enorgueillit dans l'introduction de son traité de la confiance dont le Saint-Office avait fait preuve envers lui en le nommant "familier ", reconstruit une seule théorie de la représentation là où son modèle (Paleotti) avait tenté de maintenir deux domaines séparés.

Il n'y a pas lieu de parler ici d'une prolongation consciente dans la théorie de l'image défendue par Pacheco de la théorie de la représentation pour laquelle on avait fait abjurer le docteur Egidio. D'ailleurs on demandait indifféremment aux inculpés du Saint Tribunal d' " adorer » ou juste de "vénérer » le crucifix qu'on leur présentait avant de faire leur déposition ${ }^{15}$. Mais la lecture orientée de Paleotti faite par Pacheco nous permet d'introduire les hypothèses de travail suivantes : d'abord, que leurs théories ne pouvaient être " universelles " alors qu'ils se trouvaient dans des 
contextes religieux et idéologiques différents. Entre l'Espagne et l'Italie s'ouvre dans cette approche une profonde brèche qu'il serait pertinent d'explorer et qui transparaît par exemple dans les appréciations des Italiens sur le caractère " dévot" des commandes qui leur arrivaient de la péninsule ibérique (GOLDBERG, 1998). Ensuite, on constate l'imbrication étroite de deux discours, celui des artistes et celui des théologiens, là où certains auteurs préfèrent voir une évolution marquée par leur indépendance progressive, qui pointe un "statut " particulier des images que l'on pourrait qualifier de confessionnel. Le Christ de Velázquez, mais aussi quelquesunes des plus intéressantes créations de la peinture baroque, telles que le dénominé " trampantojos a lo divino " [ " trompel'œil divin " ; fig. 6] (PÉREZ SÁnCHEZ, 1992), sont sans nul doute caractérisés par

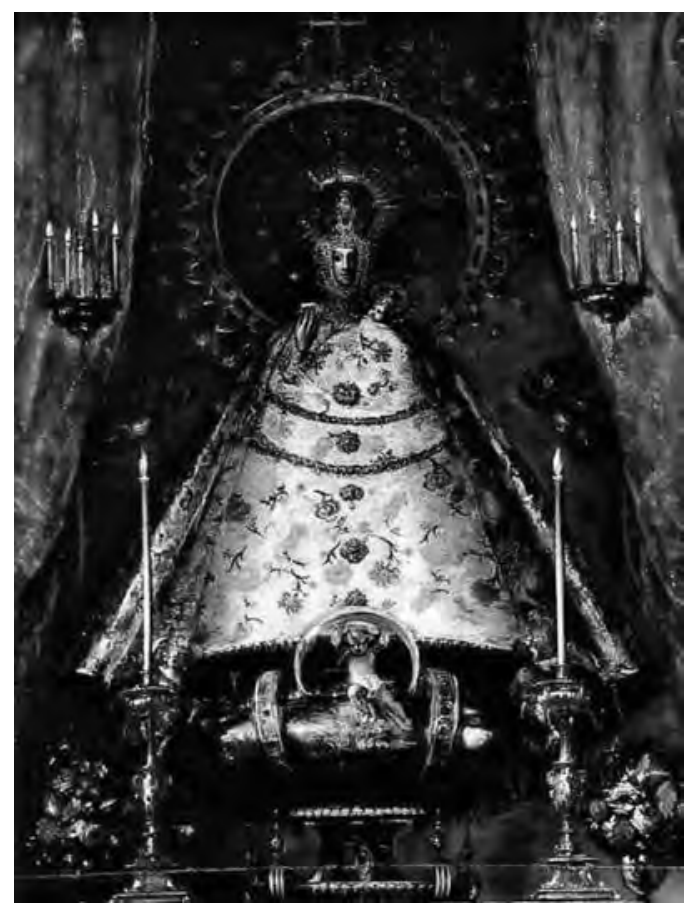

6. Juan Carreño de Miranda, La Vierge d'Atocha, dit « Trompe I'œil divin ", vers 1671, Tolède, Museo del Greco.

cette même liminalité hallucinatoire. Enfin, cette continuité entre le discours de l'image et celui de l'art, entre la théorie de la représentation défendue par le Saint-Office et celle que fit sienne Francisco Pacheco, était construite, comme nous l'avons montré, à travers des mécanismes institutionnels, et parfois disciplinaires, mais toujours ancrés historiquement et géographiquement, qui, s'ils ne les justifient pas, offrent au mieux une condition sine qua non de leur paradoxale singularité et en tout cas un nouveau point de vue pour une réflexion sur la question.

Si actuellement les études sur la peinture religieuse - un genre indiscutablement prédominant dans l'école espagnole - ont progressé grâce à la publication de nombreux catalogues et de monographies d'artistes, ce domaine souffre néanmoins toujours d'un manque de mise en contexte approprié, à l'exception de remarquables travaux mettant en regard image religieuse et histoire sociale (PORTÚS, VEGA, 1998 ; WEBSTER, 1998 ; BLACK, 2006 ; SCHMIDDUNSER, 2008). Au sein du panorama historiographique actuel, l'effort devrait passer non seulement par une plus grande attention portée à la reconstruction du contexte social et historique de ces images, mais aussi par une réflexion nécessaire sur les fondements doctrinaux qui les sous-tendent. 


\section{Notes}

1. "Raspemos un poco, y muy luego daremos [...] con la Inquisición latente y difusa, vestida con formalismo de latísima formalidad, con la gravedad, nada seria, de la vieja morgue castillane " (Miguel de Unamuno, En torno al casticismo, Madrid, [1895] 1902, trad. fr. de Marcel Bataillon : L'Essence de l'Espagne, Paris, (1923) 1967, p. 184)

2. "... viendo que unas personas que iban con el se apartaban de la sombra que hazia una cruz en el suelo por no pisarla se rrio y se puso después encima de la sombra della..." (AHN, Inq. Leg. 2075, n 35 ).

3. «... aviendo dichas personas dicho que se apartavan por no pisar la sombra de la cruz, el reo se puso encima de la dicha sombra de la cruz y dixo antes me da sobre mi cabesa y me cubre todo mi cuerpo y esto es reverenciarla y estimarla... " (AHN, Inq. Leg. 2075, nº 35).

4. «... y a la segunda proposición que el pissar tantas vezes la sonbra de la cruz en ocasión que otro la reverenciaba como cruz verdadera hera ssin duda hecho heretical. Pero si constase de sus palabras como paresia que constaba del dicho de otros testigos que no pretendia menospreciar la cruz quisá por pareserle que la sonbra de la cruz no hera cruz como la ssonra del onbre no es onbre, y por eso no se parava en pisarla no meresia calidad ninguna sino es que cayesse la tal accion en alguna persona malindiziada en cosas de fee que la hiziese sospechosa en ella " (AHN, Inq. Leg. 2075, n 35 ).

5. AHN, Inq. Leg. 2055, no 11 . Le document, rendu public par Agustín Redondo (REDONDO, 1989), a été analysé de manière plus détaillée par Stefania Pastore (PASTORE, 2004, p. 208-221).

6. "Yten dije que solo Dios se ha de adorar. Y que quando sacavan la Ymagen de Nuestra Señora ydolatravan las gentes y que si tuviera yo poder quitara aquellas ocasiones y que yo aunque no quitava las Ymagenes quitaba la adoración de ellas porque sabia de la scritura aver sido Dios gravemente offendido de la adoraçion de ellas, y tuve en esta raçon argumento de las ydolatrias del testamento viejo en todas las quales proposiciones hice vehemente sospecha que las ymagenes de Dios y de los santos no se han de adorar con la adoración que los que son por ellos representadas lo qual esta condemnado por los concilios antiguos e por ende yo en tal sentido retracto todas estas proposiciones por hereticas y como vehementemente sospechoso en ellas las abjuro confesando que adorar la ymagen no es ydolatrar porque se adora como señal donde esta representado Dios, o el sancto, y por ende a la ymagen de Dios se debe la misma adoraçion latria que al mismo Dios, y a las de los sanctos la misma adoraçion dulia que a los mismos sanctos " (AHN, Inq. Leg. 2055, nº 11).

7. "Item dije que la cruz no se avia de adorar por ser cruz, que solo Dios se avia de adorar y no otra cossa. Y dije mas que la cruz era un poco de palo, y que no tenia virtudes ninguna en lo qual hice vehemente sospecha decirlo contra la confesión e costumbre y rito de la yglesia que adora la cruz diciendo $\mathrm{O}$ crux, ave spes unica y tuam crucem adoramus por lo qual como heretica retracto la dicha proposicion y como vehemente mente sospechoso en ella la abjuro y particularmente y lo que dije que dios se avia de adorar latria adoratione y la cruz adoratione dulie antes confieso que la cruz se ha de adorar con la misma adoraçion de latria que se adora Jesuxpo porque se adora como cossa aonde esta el representado y assi digo que la cruz y las ymagenes no solo sirben de acordarnos como la scritura de Dios y de los sanctos a los quales emos de adorar sino que por señales en donde estan representados Dios y los sanctos se an de adorar ellas mesmas " (AHN, Inq. Leg. 2055, $\mathrm{n}^{\circ} 11$ ).

8. «... la cruz se ha de adorar con la misma adoraçion de latria que se adora Jesuxpo porque se adora como cossa aonde esta el representado y assi digo que la cruz y las ymagenes no solo sirben de acordarnos como la scritura de Dios y de los sanctos a los quales emos de adorar sino que por señales en donde estan representados Dios y los sanctos se an de adorar ellas mesmas" (AHN, Inq. Leg. 2055, $\mathrm{n}^{\circ} 11$ ). Les italiques sont de l'auteur.

9. En fait, il s'agissait de deux crucifix différents, voir AHN, Inq. (Tolède), Leg. 140, 4, décrits dans la documentation du procès par l'un des témoins comme de " çerca de media vara de largo " [près d'une demi verge de long] (f. 492). Détails absents de l'étude du procès, par ailleurs substantielle, de PULIDO SERRANo, 2002, qui l'a étudié en détail.

10. Comme on le sait, le lieu précis pour lequel le tableau fut peint n'est pas bien clair. Les premières informations le situent cependant dans des endroits qui auraient exigé cette contemplation rapprochée, selon Palomino "en la clausura del convento de San Plácido " (dans l'isolement du couvent de Saint-Placide), ou Ponz " en la sacristía de la Iglesia " (dans la sacristie de l'église).

11. Dans cette optique de confrontation entre l'artiste français et Velázquez, Louis Marin compare de manière inédite la démarche de Champaigne dans l'Ex-Voto du Louvre à celle employée par Velázquez dans le portrait de la Mère Jerónima de la Fuente (1620, Madrid, Museo del Prado : MARIN, 1995, p. 124-132.

12. Dans son édition critique, Bonaventura Bassegoda i Hugas (PACHECO, [1649] 1990) souligne l'ajout de Pacheco sans autre commentaire. La traduction de Pacheco est fondée sur l'édition latine De Imaginibus Sacris et Profanis, Ingolstadt, 1594.

13. "[Livre. II. Chap. 11]. Pues sea lo postrero, necesario a este discurso (si bien breve en palabras, importante en las cosas) las tres maneras de adoración que se dan a las imágenes sagradas. La primera, llamada Latría, se debe a sólo Dios Padre, y Hijo y Espíritu Santo, a sus divinas imágenes y al Santísimo Sacramento del altar [...], muestra el hombre de Latría, propiamente, el culto que se debe a la excelencia de perfección absoluta, la cual se halla sólo en el primer principio de todas las criaturas, que es el gran Dios, autor y hacedor y gobernador del universo " (PACHECO, 1990, p. 263-264).

14. "Esta mesma adoración se debe también a la más pequeña parte del madero de la Santísima Cruz en que nuestro Señor murió aunque no tenga forma de ella, por cuanto concurrió con él en la obra de nuestra redención, y por el contacto de su santísimo cuerpo y sangre preciosa; $y$ sí tiene figura de cruz, porque representa al mismo Señor clavado en ella. $Y$ de la misma manera, por esta tercera razón, debemos la mesma reverencia y adoración de latría a todas las demás cruces, de cualquiera materia que sean, porque son figuras, no sólo de la en que el Señor fue puesto, pero de su misma persona divina. La tercera especie, que se llama Dulía, es una veneración y señal de reverencia anticipada, que es cuando el Sumo Bien le ha comunicado algunos dones de su grandeza " (PACHECO, 1990, p. 264)

15. Il n'existe aucune étude ou recherche mentionnant ce point, mais c'est ce que j'ai pu constater à la lecture des procès. 


\section{Bibliographie}

- BACCI, 1998 : Michele Bacci, Il pennello dell'Evangelista. Storia delle immagini sacre attribuite a san Luca, Pise, 1998.

- Belting, (1990) 1994 : Hans Belting, "The Power of Images and the Limitations of Theologians ", dans Likeness and Presence. A History of the Image before the Era of Art, Chicago/Londres, 1990

- Belting, 2005 : Hans Belting, Das echte Bild. Bildfragen als Glaubensfragen, Munich, 2005.

-BLACK, 2006 : Charlene Villaseñor Black, Creating the Cult of St. Joseph. Art and Gender in the Spanish Empire, Princeton/ Oxford, 2006.

- BOESPFlUG, CHRISTIN, 2007 : François Boespflug, Olivier Christin, « Das Konzil von Trient und die katholischen Traktate De Imaginibus (1522-1680)", dans HOEPS, 2007, p. 241-261.

- BRAUn, 1547 : Konrad Braun, De Imaginibus sacris et profanis..., Basel, 1547. - BROWN, 1986 : Jonathan Brown, Velázquez, pintor y cortesano, Madrid, 1986.

-CATHARINUS, 1552 : Ambrosius Catharinus, De cultu et adoratione imaginum, Rome, 1552.

- Ceballos, 2004 : Alfonso Rodríguez G. de Ceballos, "El Cristo crucificado de Velázquez. Trasfondo histórico-religioso ", dans Archivo Español de Arte, 77, 2004, p. 5-19.

- Civil et al., 2008 : Pierre Civil et al. éd., La imagen religiosa en la Monarquía Hispánica. Usos y funciones, Madrid, 2008. - Cordero DE CIRIA, 1994 : Enrique Cordero de Ciria, "Proceso inquisitorial contra Gabriel Ximénez Donoso, pintor ", dans Archivo Español de Arte, 67/266, 1994, p. 171-172.

- CoRdero DE CIRIA, 1997 : Enrique Cordero de Ciria, "Arte e Inquisición en la España de los Austrias ", dans Boletín del Museo e Instituto Camón Aznar, 70, 1997, p. 29-86.

- El divino pintor..., 2001 : El divino pintor. La creación de María de Guadalupe en el taller celestial, Jaime Cuadriello éd., (cat. expo., Mexico, Museo de la Basílica de Guadalupe/Monterrey, Museo de Historia Mexicana, 2001-2002), Mexico, 2001.

- Freedberg, 1992 : David Freedberg, "Holy Images and Other Images ", dans Susan C. Scott éd., The Art of Interpreting, Penn. State University, 1992, p. 69-80.
- GÁLLEGO, 1991 : Julián Gállego, Visión y símbolos en la pintura española del Siglo de Oro, Madrid, 1991.

- GANZ, HENKel, 2004 : David Ganz, Georg Henkel éd., Rahmen-Diskurse. Kultbilder im konfessionellen Zeitalter, Berlin, 2004.

- GANZ, HENKEL, 2007 : David Ganz, Georg Henkel, "Kritik und Modernisierung. Der katholische Bildkult der konfessionellen Zeitalters", dans HoEPS, 2007, p. 261-285.

- GoldBerG, 1998 : Edward L. Goldberg, "Circa 1600: Spanish Values and Tuscan Painting ", dans Renaissance Quarterly, 51, 1998, p. 912-933.

-GRoOTEnBoer, 2005 : Hanneke Grootenboer, The Rhetoric of Perspective. Realism and Illusionism in SeventeenthCentury Dutch Still-Life Painting, Chicago/ Londres, 2005.

-Hecht, 1997 : Christian Hecht, Katholische Bildertheologie im Zeitalter von Gegenreformation und Barock: Studien zu Traktaten von Johannes Molanus, Gabriele Paleotti und anderen Autoren, Berlin, 1997. - Hoeps, 2007 : Reinhard Hoeps, Handbuch der Bildtheologie, I, Bild-Konflikt, Paderborn, 2007.

- JEDIN, (1935) 1966 : Hubert Jedin, "Entstehung und Tragweite des Trienter Dekrets über die Bilderverherung ", dans Kirche des Glaubens, Kirche der Geschichte, II, Konzil und Kirchenreform, Fribourg-enBrisgau, (1935) 1966, p. 460-498.

- JONES, 1995 : Pamela Jones, " Art Theory as Ideology: Gabriele Paleotti's Hierarchical Notion of Painting's Universality and Reception ", dans Claire Farago éd., Reframing the Renaissance: Visual Culture in Europe and Latin America 1450-1650, New Haven/Londres, 1995. p. 127-139.

- KaufmanN, 2004 : Thomas DaCosta Kaufmann, Toward a Geography of Art, Chicago/Londres, 2004.

- KRÜGER, 2001 : Victor Krüger, Das Bild als Schleier des Unsichtbaren. Ästhetische Illusion in der Kunst der frühe Neuzeit in Italien, Munich, 2001.

- MARIN, 1985 : Louis Marin, "Imitation et trompe-l'œil dans la théorie classique de la peinture au XVII ${ }^{\text {e }}$ siècle", dans Rencontres de l'École du Louvre, L'imitation, aliénation ou source de liberté ?, Paris, 1985, p. 181-196.
- MARIN, 1994 : Louis Marin, "Représentation et simulacre", dans Louis Marin et al., De la représentation, Paris, 1994, p. 303-312.

- MARIN, 1995 : Louis Marin, Philippe de Champaigne ou la présence cachée, Paris, 1995.

- NAGEL, 2000 : Alexander Nagel, Michelangelo and the Reform of Art Cambridge, 2000.

- ORY, 1552 : Mattheaus Ory, De cultu imaginum, Rome, 1552.

- PACHECO, (1649) 1990 : Francisco Pacheco, El arte de la pintura, (1649), Bonaventura Bassegoda i Hugas éd. Madrid, 1990.

- PAleotti, (1582) 2002 : Gabriele Paleotti, Discorso intorno alle immagini sacre e profane, (Bologne, 1582), Stefano della Torre éd., Rome, 2002.

- PASTORE, 2004 : Stefania Pastore, Un'eresia Spagnola. Spiritualità conversa alumbradismo e inquisizione (1449-1559), Florence, 2004.

- PeredA, 2007 : Felipe Pereda, Las imágenes de la discordia. Política y poética de la imagen sagrada en la España del 400, Madrid, 2007.

- PÉREZ DE AyAlA, 1548 : Martín Pérez de Ayala, De divinis, apostolicis, et eclesiasticis traditionibus, Augsbourg, 1548.

- PÉREZ SÁNCHEZ, 1992 : Alfonso Emilio Pérez Sánchez, "Trampantojos 'a lo divino' ", dans Lecturas de Historia del Arte, III, 1992, p. 139-155.

- PINTO, 1978 : Virgilio Pinto Crespo, " La actitud de la Inquisición ante la iconografía religiosa. Tres ejemplos de su actuación (1571-1665)", dans Hispania Sacra, 31, 1978, p. 285-322.

- Portús, VeGA, 1998 : Javier Portús, Jesusa Vega, La Estampa religiosa en la España del Antiguo Régimen, Madrid, 1998. - PRODI, 1965 : Paolo Prodi, "Ricerche sulla teorica delle arti figurative nella Riforma cattolica ", dans Archivio italiano per la storia della Pietà, 4, 1965, p. 123-212. - Pulido, 2002 : Juan Ignacio Pulido Serrano, Injurias a Cristo. Religión, política y antijudaísmo en el siglo XVII. Alcalá de Henares, 2002.

- REDONDO, 1989 : Augustín Redondo, « El doctor Egidio y la predicación evangelista en Sevilla durante los años 1535 1549 ", dans Juan Luis Castellano, Francisco Sánchez-Montes éd., Carlos V. Europeísmo y universalidad, Francfort, 1989, p. 65-88. 
- SÁNCHEZ, 1989 : Natividad Sánchez Esteban, "Pinturas en el Colegio de Doña María de Aragón: problemas inquisitoriales ", dans Cuadernos de Arte e Iconografía, 2/4, 1989, p. 106-116

- SÁNCHEZ, 1991 : Natividad Sánchez Esteban, "Sobre los Arcángeles", dans Cuadernos de Arte e Iconografía, 4/8, 1991, p. 91-101.

-SCAVIZZI, 1992 : Giuseppe Scavizzi, The Controversy on Images From Calvin to Baronius, New York, 1992.

- SCHMIDDUNSER, 2008: Agathe Schmiddunser, Körper der Passionen. Die lebensgrosse Liegefigur des toten Christus vom Mittelalter bis zum spanischen Yacente des Frühbarock, Regensburg, 2008.

- SCHMitT, 2002 : Jean-Claude Schmitt, Le corps des images essais sur la culture visuelle au Moyen Âge, (Le Temps des images, 13), Paris, 2002.
- SCHOLZ-HÄNSEL, 1994 : Michael ScholzHänsel, "¿La Inquisición como mecenas?: imágenes al servicio de la disciplina y de la propaganda inquisitorial ", dans Boletín del Seminario de Estudios de Arte y Arqueología de la Universidad de Valladolid, 60, 1994, p. 301-320.

- SCHRAEDER, 2008 : Jeffrey Schraeder, La Virgen de Atocha. Los Austrias y las imágenes religiosas, Madrid, 2008.

- SteINEMANN, 2006 : Holger Steinemann, Eine Bildtheorie zwischen Repräsentation und Wirkung. Kardinal Gabriele Paleottis "Discorso intorno alle imagini sacre e profane", Hildesheim, 2006.

- STOICHITA, 1993 : Victor Stoichita, L'instauration du tableau. Métapeinture à l'aube des Temps modernes, Paris, 1993.

- STOICHitA, 1996 : Victor Stoichita, El ojo místico. Pintura y vision religiosa en el Siglo de Oro español, Madrid, 1996.
- THunø, 2004 : Eric Thunø, Gerhard Wolf, éd., The Miraculous Image in the Late Middle Ages and Renaissance, Rome, 2004.

- WeBster, 1998 : Susan Verdi Webster, Art and Ritual in Golden Age Spain. Sevillian Confraternities and the Processional Sculpture of the Holy Week, Princeton, 1998.

- WIRTH, 2000 : Jean Wirth, "La critique scolastique de la théorie thomiste de l'image ", dans Olivier Christin, Dario Gamboni éd., Crises de l'image religieuse : de Nicée II à Vatican II, Paris, 2000, p. 93-109. - WOLF, 1990 : Gerhard Wolf, Salus Populi Romani. Die Geschichte römischer Kultbilder im Mittelalter, Weinheim, 1990.

- WOLF, 2002 : Gerhard Wolf, Schleier und Spiegel. Traditionen des Christusbildes und die Bildkonzepte der Renaissance, Munich, 2002. 